Linköping Studies in Science and Technology

Dissertation No. 2016

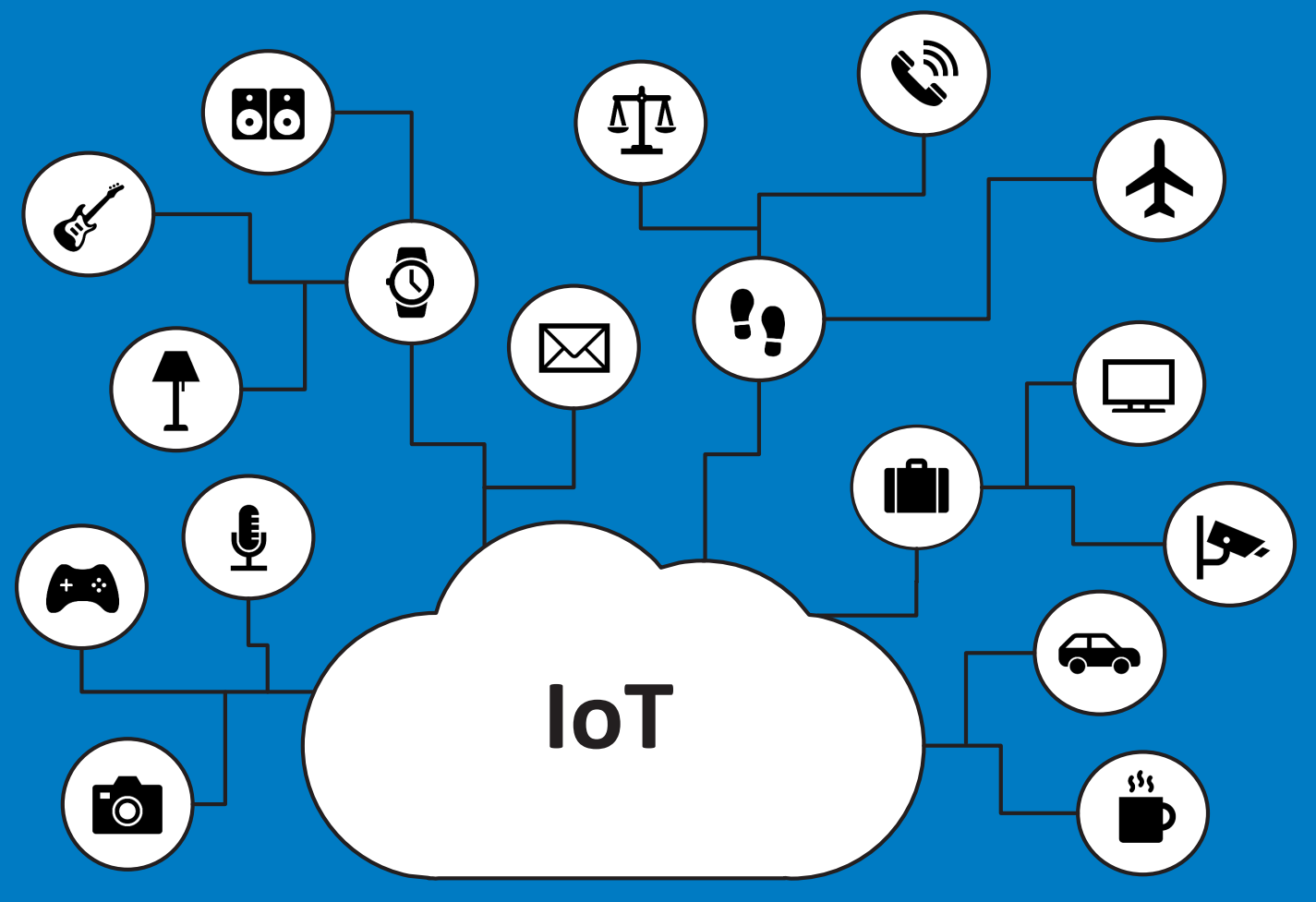

Cooperation and Resource Allocation in Wireless Networking

towards the IoT

loannis M. Avgouleas 


\section{Cooperation and Resource Allocation in Wireless Networking towards the IoT}

Ioannis M. Avgouleas 
Cooperation and Resource Allocation in Wireless Networking towards the IoT

Ioannis M. Avgouleas

Linköping Studies in Science and Technology. Dissertations, No. 2016

Copyright $\odot 2019$ Ioannis M. Avgouleas, unless otherwise noted

ISBN 978-91-7519-004-4

ISSN $0345^{-7524}$

Printed by LiU Tryck, Linköping, Sweden 2019 


\section{Abstract}

The Internet of Things (IoT) should be able to react with minimal human intervention and contribute to the Artificial Intelligence (AI) era, requiring real-time and scalable operation under heterogeneous network infrastructures. This thesis investigates how cooperation and allocation of resources can contribute to the evolution of future wireless networks supporting the IoT.

First, we examine how to allocate resources to IoT services which run on devices equipped with multiple network interfaces. The resources are heterogeneous and not interchangeable, while their allocation to a service can be split among different interfaces. We formulate an optimization model for this allocation problem, prove its complexity, and derive two heuristic algorithms to approximate the solution in large instances of the problem. Our results can act as a guide for designing IoT applications e.g., to simulate the power drain of a battery-operated IoT device.

The concept of virtualization is promising towards addressing the heterogeneity of IoT resources by providing an abstraction layer between software and hardware. Network function virtualization (NFV) decouples traditional network operations such a routing from proprietary hardware platforms and implements them as software entities known as virtualized network functions (VNFs). In the second paper, we study how VNF demands can be allocated to Virtual Machines (VMs) by considering the completion-time tolerance of the VNFs. We prove that the problem is NP-complete and, thus, we devise a subgradient optimization algorithm to provide near-optimal solutions. Our numerical results demonstrate the effectiveness of our algorithm compared to two benchmark algorithms.

Furthermore, we explore the potential of using intermediate nodes, the socalled relays, in IoT networks. In the third paper, we study a multi-user random access network with a relay node assisting users in transmitting their packets to a destination node. We provide analytical expressions for the performance of the relay's queue and the system throughput. We optimize the relay's op- 
eration parameters to maximize the network-wide throughput while maintaining the relay's queue stability. A stable queue at relay guarantees finite delay for the packets. Furthermore, we study the effect of the wireless links' signalto-interference-plus-noise ratio (SINR) threshold and the self-interference (SI) cancellation on the per-user and network-wide throughput.

Additionally, caching at the network edge has recently emerged as an encouraging solution to offload cellular traffic and improve several performance metrics of the network such as throughput, delay and energy efficiency. In the fourth paper, we study a wireless network that serves two types of traffic: cacheable and non-cacheable traffic. In the considered system, a wireless user with cache storage requests cacheable content from a data center connected with a wireless base station. The user can be assisted by a pair of wireless helpers that exchange non-cacheable content as well. We devise the system throughput and the delay experienced by the user and provide numerical results that demonstrate how the non-cacheable packet arrivals, the availability of caching helpers, the parameters of the caches, and the request rate of the user affect them.

Finally, in the last paper, we consider a time-slotted wireless system that serves both cacheable and non-cacheable traffic with the assistance of a relay node. The latter has storage capabilities to serve both types of traffic. We investigate how allocating the storage capacity to cacheable and non-cacheable traffic affects the system throughput. Our numerical results provide useful insights into the system throughput e.g., that it is not necessarily beneficial to increase the storage capacity for the non-cacheable traffic to realize better throughput at the non-cacheable destination node. 


\section{Populärvetenskaplig sammanfattning}

Internet of Things (IoT) -tjänster bör kunna reagera med minimalt mänskligt ingripande och bidra till AI-eran, vilket kräver skalbar drift i realtid med heterogen infrastruktur. Denna avhandling undersöker hur samarbete och allokering av resurser kommer att bidra till utvecklingen av framtida trådlösa nätverk som stöder IoT.

Först hanterar vi resursallokering till IoT-tjänster som körs på enheter utrustade med flera nätverksgränssnitt. Resurserna är heterogena och inte utbytbara medan deras tilldelning till en tjänst kan delas mellan olika gränssnitt. Vi formulerar en optimeringsmodell för detta allokeringsproblem och bevisar dess NP-fullständighet, vilket leder till att vi härleder två heuristiska algoritmer för att närma sig lösningen i stora instanser av problemet. Våra resultat kan fungera som en guide för design och implementering av verkliga IoT-applikationer och parametrar, till exempel för att simulera strömförbrukning för en batteridriven IoT-enhet.

Begreppet virtualisering är lovande för att addressera heterogeniteten i IoT-resurser genom att tillhandahålla ett abstraktionslager mellan mjukoch hårdvara. NFV (Network Function Virtualisation) separerar traditionella nätverksoperationer, såsom ruttning av paket från egna hårdvaruplattformar och implementerar dem som mjukvaruenheter kända som virtualiserade nätverksfunktioner (VNF). I den andra artikeln studerar vi hur virtuella nätverksfunktioners efterfrågan kan allokeras till virtuella maskiner genom att använda den virtuella nätverksfunktionens tolerans för när ett visst paket måste ha hanterats. Vi bevisar NP-fullständigheten för problemet och utvecklar en algoritm baserad på Lagrange-relaxering och subgradientoptimering för att åstadkomma när-optimala lösningar. Dessutom visar våra numeriska resultat 
den föreslagna algoritmens effektivitet jämfört med två referensalgoritmer.

Vidare undersöker vi möjligheterna i att använda förmedlingsnoder i IoT-nätverk. I den tredje artikeln studerar vi ett fleranvändarnätverk med slumpmässig åtkomst med en förmedlingsnod som assisterar användare i att skicka sina paket till slutdestinationen. Vi tar fram analytiska uttryck för prestanda gällande förmedlingsnodens kölängd och nätverkets genomströmning. Vi optimerar förmedlingsnodens driftparametrar för att maximera den totala genomströmningen i nätverket medan vi bibehåller förmedlingsnodens köstabilitet. En stabil kö i förmedlingsnoderna garanterar en ändlig fördröjning för de förmedlade paketen. Vidare studerar vi effekten av de trådlösa länkarnas tröskelvärde för signal-till-brus-och-interefrensförhållande (SINR) samt cancellering av interferensen från den egna enheten i termer av användar- och nätverksgenomströmning.

Lokal lagring av data (eng. "cache") i utkanten av nätverket har nyligen kommit upp som en potentiell lösning för att avlasta mobilnät och förbättra flera typer av prestandamått för nätverket, så som genomströmning, fördröjning och energieffektivitet. I den fjärde artikeln utvärderar vi ett trådlöst system där vi skiljer mellan lokalt lagringsbar och icke lokalt lagringsbar trafik. Vi analyserar ett system där en trådlös användare med begränsad lokal lagring begär lokalt lagringsbart innehåll från ett datacenter som kan nås direkt via en basstation. Användaren kan stödjas av ett par trådlösa hjälpare som också utbyter icke lokalt lagringsbart innehåll. Vi analyserar systemets genomströmning och fördröjningen som användaren upplever och visar genom numeriska resultat hur detta påverkas av ankomstintensiteten för icke lokalt lagringsbar trafik, tillgängligheten för hjälparna, parametrar för lokal lagring och användarens intensitet av förfrågningar.

Slutligen, i den sista artikeln, analyserar vi ett trådlöst system med tidsluckor som stödjer både lokalt lagringsbar och icke lokalt lagringsbar trafik med hjälp av en förmedlingsnod. Förmedlingsnoden har lagringskapacitet för att hantera båda typerna av trafik. Vi analyserar hur fördelningen av lagringskapaciteten mellan den lagringsbara och icke lokalt lagringsbara trafiken påverkar systemets genomströmning. Våra numeriska resultat ger användbara insikter i systemets genomströmning, till exempel att det inte nödvändigtvis är effektivt att öka lagringskapaciteten för den icke lokalt lagringsbara trafiken för att åstadkomma bättre genomströmning vid slutnoden som inte har stöd för lokal lagring av trafik. 


\section{Acknowledgements}

First and foremost, I would like to thank my supervisor, Associate Professor Vangelis Angelakis, who gave me the opportunity to cooperate with him. It has been an honor to be his first Ph.D. student. I appreciate all his indispensable contributions of effort, time, and courage to make my Ph.D. journey a pleasant experience. His advice on research, time management, as well as life's issues has been priceless.

A special thanks to my co-supervisor, Associate Professor Nikolaos Pappas. Words alone cannot express how much I appreciate the extensive support, discussions, and ideas he has generously shared with me; nor the attitude towards science and life that he has incited me to strive towards.

I would also like to express my sincere gratitude to Professor Di Yuan for providing me with precious help, brilliant comments, thoughtful discussions, guidance, and financial support to conduct parts of my research. I am also thankful to Associate Professor Marian Codreanu who was always willing to share his mindset and scientific expertise with me. I will never forget how helpful my mentor David Gundlegård has been especially at the end of my PhD life. All I can say is thanks.

I gratefully acknowledge the funding sources of my Ph.D work. My graduate research was supported by the European Union's Seventh Framework Programme FP7/2007-2013/ under Grant 609094 (RERUM), 612361 (SOrBet), 324515 (MESH-WISE), 645705 (DECADE), 318992 (WINDOW), 990881 (VINNOVA MODE), 301617 (Latency Control), and teaching assistance grants from the Department of Science and Technology (ITN) at Linköping University.

My time at Norrköping was made enjoyable largely due to my friends Nikos, Manos, Cristian, Christos, Antzela, Maria, Elina, Xenos, Eleni, Yannis, Zheng, and my colleagues at Department of Science and Technology. I am grateful for time spent with roommates and my backpacking buddies on our trips around the world. I really appreciate the patience demonstrated by Lei Lei, Qing He, 
Lei You, Ngoc, Manos, Bolin, and all my colleagues in Milano, Wuhan, Athens, Barcelona, and Cambridge who shared the office with me.

Lastly, I would like to express my gratitude to my parents and my brothers whose tremendous support during the stages of this Ph.D. is so appreciated. Thank you.

Norrköping, December 2019

Ioannis Avgouleas 



\section{Acronyms}

AI Artificial Intelligence

BA Buffer-Aided

BAN Body Area Network

BBU Baseband Unit

BP Back-Pressure

CAPEX Capital Expenditure

CDN Content Delivery Network

CoAP Constrained Application Protocol

CR Cooperative Relaying

CSI Channel State Information

D2D Device-to-device

DAU Data Aggregator Unit

DTMC Discrete Time Markov Chain

FD Full-Duplex

HD Half-Duplex

HVS High Volume Server

I/O Input/Output

ICT Information and Communication Technologies 
IoT Internet of Things

IP Integer Program

IRM Independent Reference Model

ISP Internet Service Providers

ITS Intelligent Transport Systems

LA Link Activation

LAN Local Area Network

LFU Least Frequently Used

LoRa Long Range

LP Linear Program

LPWAN Low-Power Wide Area Networks

LRU Least Recently Used

LS Link Scheduling

LTE Long-Term Evolution

LTE-A LTE Advanced

M2M Machine-to-machine

MAC Medium Access Control

MILP Mixed Integer linear programming

MPC Most Popular Content

MPR Multiple Packet Reception

MQTT Message Queue Telemetry Transport

MTC Machine-Type Communications

MTD Machine-Type Devices

NB-IoT NarrowBand Internet of Things

NF Network Function

NFV Network Function Virtualization 
NFV-MANO NFV Management and Orchestration

NLP Non-Linear Problem

NP Non-deterministic Polynomial-time complete

NP-complete Non-deterministic Polynomial-time complete

NS Network Services

OPEX operational expenditure

OS Operating System

PHY Physical (layer)

PP Partition Problem

QoS quality of service

RA Resource Allocation

RFID Radio-frequency identification

SI Self-Interference

SIA Services-to-Interfaces Assignment

SINR Signal-to-Interference-plus-Noise Ratio

SNR Signal-to-Noise Ratio

UE User Equipment

V2V vehicle-to-vehicle

VDTN vehicular delay-tolerant network

VM Virtual Machine

VMM Virtual Machine Monitor

VNF Virtualized Network Function

VNFI Virtualized Network Function Infrastructure

VO virtual object 
VWAN very wide area network

WAN wide area network

WSN Wireless Sensor Networks 


\section{Contents}

Abstract

Populärvetenskaplig sammanfattning $\mathrm{v}$

Acknowledgements vii

Acronyms $\quad$ xi

I Introduction and Overview 1

1 Introduction 3

1.1 Motivation 3

$\begin{array}{lll}1.2 & \text { Thesis Outline and Organization } & 7\end{array}$

2 Cooperation and Resource Allocation 9

2.1 Resource Allocation in Wireless Networking 10

2.2 Cooperative Relaying 12

2.3 Network Function Virtualization (NFV) 14

$\begin{array}{lll}2.4 & \text { Caching } & 16\end{array}$

3 Mathematical Modeling $\quad 19$

3.1 Mathematical Optimization 19

3.1.1 Optimization Algorithms 20

3.2 Queueing Theory 22

3.2.1 Queueing Systems 22

3.2.2 The discrete time Birth-Death (BD) Process 22

3.2.3 Geo/Geo/1 Queues 24

3.2.4 Geo/Geo/1/K Queues 24 
4 Contributions $\quad 25$

$\begin{array}{lll}4.1 & \text { Summary of papers } & 26\end{array}$

$\begin{array}{ll}\text { Bibliography } & 31\end{array}$

II Included Papers $\quad 43$

$\begin{array}{ll}\text { Paper I } & 47\end{array}$

$\begin{array}{lr}\text { Paper II } & 81\end{array}$

$\begin{array}{ll}\text { Paper III } & 97\end{array}$

$\begin{array}{ll}\text { Paper IV } & 129\end{array}$

$\begin{array}{ll}\text { Paper V } & 167\end{array}$ 
Part I

\section{Introduction and Overview}





\section{Chapter 1}

\section{Introduction}

\subsection{Motivation}

The Internet of Things (IoT) is an innovative concept which encompasses a massive number of heterogeneous objects with different computing, storage, and networking capabilities with the aim of providing an interpretation of the physical world through the Internet [1]. A variety of devices from simple ones capable of communicating just their positions to objects with advanced sensing capabilities will contribute to the IoT realization. The IoT will enable physical objects to see, listen, and perform tasks by cooperating, sharing information, and taking common decisions [2], [3]. Consequently, many of these objects will be transformed from being basic to being smart by exploiting IoT's embrace of Information and Communication Technologies (ICT) such as pervasive computing, embedded devices, wireless sensor networks as well as Internet protocols and applications (see Fig. 1.1).

Since the IoT will comprise of objects with constrained resources that include a broad range of communication protocols with the intention of providing real-world intelligence, many issues call for addressing. An indicative list of them can be found in [5]:

- Heterogeneity i.e., the integration of several technologies and communication solutions; each one with its own characteristics and application domains. This fragmentation burdens interoperability and a unified solution is still an open issue. 


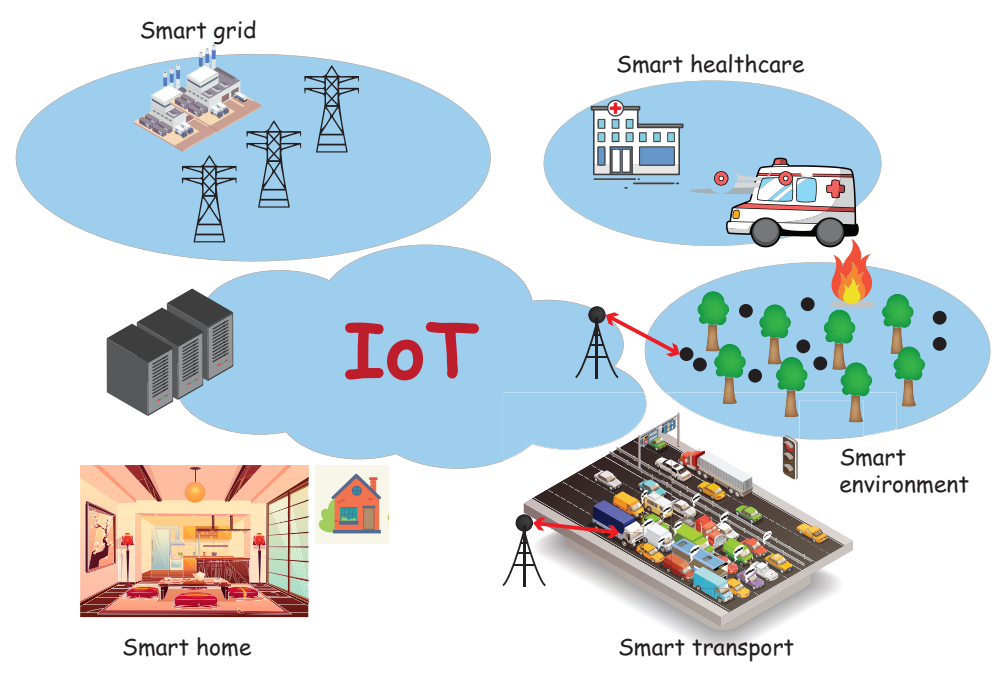

Figure 1.1: Representative IoT scenarios: smart grid, smart home, wireless sensor networks, smart transportation and smart healthcare [4].

- Scalability i.e., the ability of an IoT system to cope with a number of objects that are several orders of magnitude higher than that of the traditional Internet [6].

- Identification i.e., identifying a device in the system with a unique ID. Recently, several solutions have been proposed for resource-constrained environments such as the IoT [7]. Some examples include the Constrained Application Protocol (CoAP) [8] and Message Queue Telemetry Transport (MQTT) [9].

- Plug and Play i.e., the ability to make a device visible to the network without any human administrative intervention. The challenge in an IoT system is to make this process automatic regardless of the heterogeneity of the devices.

- Search and Discovery i.e., the dynamic discovery of the services provided by the distributed objects necessary to deploy an application to the IoT. Discovery mechanisms allow devices to automatically register themselves and offer their services in the network [10], [11].

- Constrained Resources such as processing, storage, and energy can impose severe limitations on the performance of the IoT. Resource management is therefore required. Cooperation among objects and the development of 
resource allocation methods are promising towards addressing this issue.

- Quality Management refers to the system operations that ensure that several quality requirements such as delay, packet loss, throughput, etc., in the IoT are satisfied. This is particularly problematic in IoT since end-toend quality management in highly heterogeneous networks typically requires high operational costs and performance tradeoffs [12], [13].

- Mobility i.e., seamless connectivity regardless of the objects' location or moving pattern. Objects can move either intra-domain i.e., between different cells of the same system, or inter-domain i.e., between different backbones, protocols, technologies and service providers. The former is supported by several protocols [14], while the latter is generally more difficult [15], [16].

- Security and Privacy such as requirements for resiliency to security attacks and privacy breaches, data authentication, and access control. The challenge is fulfilling this requirement in a holistic manner since even if every object might be safe by itself, the interaction with other objects might raise security issues.

To address the aforementioned difficulties there is a need for solutions that enhance the functionalities of the physical objects to allow them to talk to each other. Major IoT platforms have adopted the concept of the virtual object (VO) to bridge the gap between the physical and the virtual world. The virtual object is the digital counterpart of any physical object (or, interchangeably, entity) in the IoT including any human or lifeless, static or mobile, solid or intangible entity [5]. Virtual objects can be used to address some key issues in the IoT such as: quickly deploying new network elements by connecting VOs to external services, co-existence of heterogeneous network architectures within a common infrastructure, and always-on connectivity even if the physical object is unavailable.

Moreover, virtualization allows interoperability between heterogeneous objects through semantic representations thereby enabling them with the functionality of sensing and processing information concerning their environment. Additionally, it enhances existing functionalities in the IoT by supporting new address and naming schemes, improving objects mobility, exploiting the discovery of services, and providing accounting and secure authentication to the objects.

Considering the aforementioned discussion we conclude that connectivity 
and content-centric networking is of utter importance in the IoT as an ecosystem of devices, protocols, services, and networks [17]. At the core of this ecosystem there must be a seamless flow between:

- the Body Area Network (BAN) e.g., smart watches, e-health sensors,

- the Local Area Network (LAN) e.g., a university network,

- the wide area network (WAN) e.g., the ATM network of bank cash dispensers,

- the very wide area network (VWAN) e.g., a smart city as e-government services everywhere.

BANs allow people to be tracked and monitored. Example applications include future health care systems whose specialists and patient do not coexist in the same location. The IoT permits not only tracking and monitoring, but also tracing people's health history thereby making the whole process of healthcare more efficient and convenient. Future smart homes will exploit their LAN to gain awareness regarding the state of the building in terms of resources usage e.g., water and energy consumption, security issues e.g., theft, fire, etc., and comfort. In such settings, several actors have to cooperate: Internet Service Providers (ISP), device manufacturers, utility and security companies to name a few. Thus, the IoT is expected to bring profound benefits orchestrating all these entities.

IoT services have emerged in the context of Intelligent Transport Systems (ITS) towards improving reliability, efficiency, quality of service (QoS), and safety of the transportation infrastructure and vehicle-to-vehicle $\left(\mathrm{V}_{2} \mathrm{~V}\right)$ communication systems [1]. In transport logistics, the IoT can tremendously improve the global supply chain via intelligent cargo management. A WAN connecting all entities of a supply chain system, comprising objects and the appropriate software, can generate the resulting supply chain in real-time. The IoT can support the continuous and seamless synchronization of supply chain information along with the real-time tracking of objects.

In the smart cities context, the information collected by the environment can be exploited by city authorities to optimize the city's operations as well as by citizens to take better decisions regarding their quality of life. Moreover, the communicating entities are no longer tied to physical locations since the cities' e-government services are available everywhere due to the cities' VWAN. The IoT will not only contribute to facilitate these operations, but also to preserve people's privacy and prevent disclosure of any sensitive information to third parties [4]. 
To realize this potential, innovative technologies and services are necessary to satisfy markets and customers' needs. Additionally, devices need to be developed to fit customer requirements towards the IoT's promise that "anything that can be connected, will be connected". Wireless communication technologies connect heterogeneous physical objects together through wireless links that are lossy and noisy. IoT nodes that operate using low power and protocols such as Wi-Fi, Bluetooth, Zigbee, Long Range (LoRa), IEEE 802.15.4, Long-Term Evolution (LTE), LTE Advanced (LTE-A) and the upcoming fifth generation (5G) of cellular network technology, among others.

Resource allocation for wireless networks has been extensively studied with numerous techniques addressing issues from every layer of the ISO/OSI model. Cross-layer control and resource allocation (from the physical to transport layers) in wireless network architectures has attracted considerable attention due to its potential to support information transfer between various layers [18]. However, a fundamental issue i.e., how to serve wireless devices with heterogeneous demands by allocating limited network resources to them, remains still relevant.

Motivated by the necessity of the aforementioned arising challenges, this thesis addresses resource allocation and performance analysis problems for IoT systems with the intention of introducing and justifying cooperation among communicating devices. The main objective is of this dissertation is to optimize the performance of IoT systems. We address the problems using optimization approaches as well as queueing theory analysis where necessary. We believe that the results provide insights into the resource management of upcoming wireless network technologies.

\subsection{Thesis Outline and Organization}

The thesis is divided in two parts. In the first part, we provide a general introduction into the concepts of resource allocation, cooperative relaying, network function virtualization, and caching related to our work, along with the mathematical tools we used to approach the proposed problems. Part II contains the five research papers that complete this dissertation. 



\section{Chapter 2}

\section{Cooperation and Resource} Allocation

Cooperative techniques and resources allocation play a key role in the Capital Expenditure (CAPEX) and operational expenditure (OPEX) for deploying IoT systems. The communication network must take into account very demanding and often opposing requirements including throughput, coverage, latency, timeliness of information, and reliabililty, among others.

The latest generation of cellular networks, ${ }_{4} \mathrm{G}$, and more specifically, LTE and LTE-A undoubtedly facilitate IoT connectivity by offering extensive coverage, access to dedicated spectrum, relatively low deployment costs, and simplicity of management to name a few. Nonetheless, they are primarily designed for broadband communications and, hence, do not efficiently support every possible IoT configuration e.g., Machine-Type Communications (MTC).

The advent of $5 \mathrm{G}$ is expected to disrupt wireless communications by offering increased data rates, ultra-high reliability, ultra-low latency, and improved coverage thereby satisfying the stringent requirements of many IoT devices. However, the proliferation of IoT devices and the anticipated rapid increase in mobile traffic require novel techniques for addressing the upcoming issues (see Introduction). This thesis focuses on cooperation and resource allocation issues in IoT networks. In this chapter, we provide a brief introduction in the concepts and the techniques that shaped the approaches we present in the thesis. 


\subsection{Resource Allocation in Wireless Networking}

Resource allocation for wireless networks has been extensively studied. Crosslayer control and resource allocation from the physical to transport layers in wireless network architectures such as cellular, ad-hoc, sensor as well as hybrid wireless-wireline networks has been presented in [18]. The proliferation of the IoT will necessitate the development of networks comprising of billions of smart devices requiring ultra-high reliability, ultra-low latency and enhanced QoS [19]. Surveys of technologies and applications of IoT can be found in [1], [2], [20], [21].

The NarrowBand Internet of Things (NB-IoT) has drawn the attention of numerous researchers and standardization working groups for addressing the needs of Low-Power Wide Area Networks (LPWAN). The specification of NBIoT targets low-powered e.g., battery operated, IoT devices that are delay tolerant or located in areas where signal transmission is bad [22]. NB-IoT provides great flexibility for the massive deployment of such devices by reusing the existing network infrastructures e.g., GSM or LTE. Representative applications of IoT services supported by NB-IoT include smart agriculture, industrial control, smart metering, municipal infrastructure and so on [23]. Towards supporting the aforementioned applications, the NB-IoT requirements encompass (i) lowpower consumption, (ii) low channel bandwidth, (iii) low deployment cost for UEs and the network infrastructure, (iv) support for a massive number of devices with IP and non-IP data, and (v) extended coverage [24].

Regarding long range wireless communications, the LoRa technology has also been proposed as an infrastructure solution for the Internet of Things. A deep analysis of LoRa's component can be found in [25]. Moreover, a security analysis of several LPWAN protocols including LoRa, NB-IoT, Sigfox, and $\mathrm{DASH}_{7}$ can be found in [26]. Therein, techninal differences among LPWAN protocols are identified and compared in terms of their QoS, battery lifetime, latency, network coverage, deployment model, cost etc.

One of the most prolific strategies for resource allocation of wireless multi-hop network is based on the Back-Pressure (BP) algorithm [27]-[30]. BP based scheduling and routing typically observe the queue length information and prioritize the data packets as normal, high, and emergency to schedule the data packets to pass through a queueing network efficiently. Numerous works have appeared in the literature of BP protocols. They are shown to provide efficient resource allocation in terms of throughput optimality, load-aware routing, priority-aware routing etc. A recent survey on contemporary $\mathrm{BP}$ 
protocols and future directions on regarding BP can be found in [31].

Wireless Sensor Networks (WSNs) is one of the most important components of IoT systems. They are primarily meant to collect data from the environment and transfer it to central or distributed controllers for further processing [32]. Compared to conventional WSNs, sensors in the IoT are supposed to be smarter by making, even without human intervention, optimal decisions given their constrained resources and the dynamic nature of the IoT environment [33]. Even though, there are research works regarding resource allocation in WSNs, such as [34]-[37], they are not directly applicable to the IoT due to its more dynamic nature and connectivity requirement for billions of heterogeneous devices. Consequently, many new challenges arise and innovative approaches with higher efficiency and flexibility urge for development [38].

Numerous approaches employing mathematical optimization for resources allocation tailored for wireless networks have appeared recently. Besides widely used performance metrics, such as transmission rates, fairness, routing etc., several new metrics have also been considered. For instance, the authors in [39] consider the power covering with overlaps i.e., how to cover service areas by satisfying coverage overlaps between adjacent cells, or the number of simultaneously activated links in a shared channel. The latter is known as the Link Activation (LA) problem; a fundamental radio resource management problem [40], [41]. LA is key to Link Scheduling (LS) that examines the planning of links' transmission in a common medium [42]. A contemporary work that focuses on the LS problem with respect to emptying the demands in minimum time can be found in [43].

Apart from the previously mentioned approaches, pricing-based approaches have been widely applied in IoT systems [44]. Their popularity can be mainly attributed to their revenue generation perspective. Pricing approaches usually determine the optimal interactions among different objectives and constraints that might belong to different IoT entities e.g., sensors, User Equipment (UE), service providers, network operators etc. Innovative sensing paradigms e.g., participatory sensing and crowdsensing networks, can be realized via employing pricing and payment strategies, such as incentive mechanisms, with the intention of improving accuracy, coverage, and timeliness of sensing results. Additionally, pricing models e.g., auctions, can be employed to select sensors with the highest remaining resources thereby maximizing the network lifetime while maintaining a given QoS. 


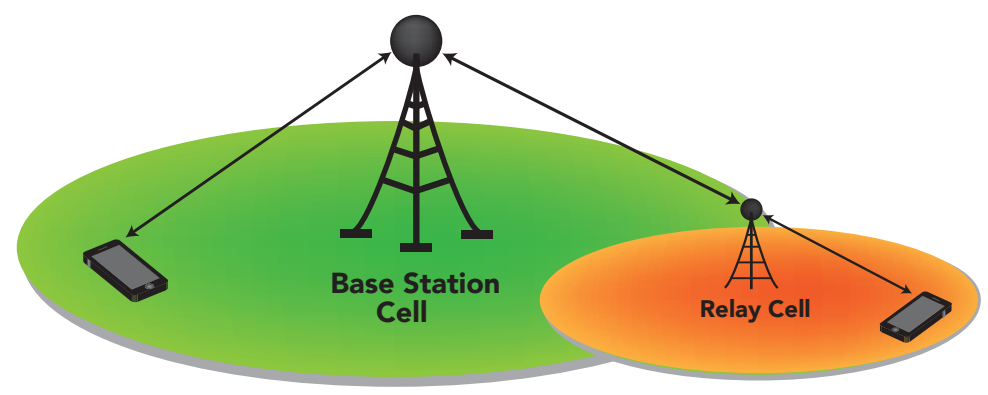

Figure 2.1: A relay node extending the coverage of the base station cell enabling communication between the two user devices.

\subsection{Cooperative Relaying}

Cooperative Relaying $(\mathrm{CR})$ is a technique used in networks in which the source and the destination node communicate through one or more intermediate nodes. In such network settings, the source and destination might not necessarily communicate directly, hence the need for intermediate nodes to relay the information to its destination (see Fig. 2.1). The intermediate nodes are usually called relay nodes and their prospective has been investigated even if there is a direct communication link between the source and the destination [45], [46]. CR has attracted significant attention in wireless networking lately due to its potential to improve various performance metrics such as outage probability, coverage, throughput, energy efficiency, and delay [47], [48].

Several gains can be obtained using relays since: (i) the communication is multi-hopped i.e., the transmitter is closer to the receiver, (ii) diversity is increased due to the additional independent wireless links, and (iii) in crowded environments, appropriate relay positioning can exploit better channel conditions and, hence, mitigate shadowing and improve the capabilities of the relayed network [49]. However, since relaying requires two or more hops for the information to reach the intended destination, a trade-off can arise between the previously mentioned gains versus the use of increased network resources (e.g., relays, coordination costs, etc.) and end-to-end delay [50], [51].

Relays have provided an extraordinary number of contributions the past ten to fifteen years. Relaying architectures have already been included in LTE [52], LTE-A [53] and IEEE WiMAX [54]. An overview of the challenges and solutions for the implementation of relaying architectures in LTE can be found in [55]. Recently, the emergence of Buffer-Aided (BA) relays has further contributed to the 
performance of cooperating relaying technologies. BA relays are able to store packets in their buffer with the intention to transmit them when the wireless channel conditions are favorable. Under circumstances, BA relays can increase the network's resiliency, throughput, diversity, energy efficiency, and delay [56], [57].

The BA relay selection model has emerged as a solution on the best relay selection among a cluster of relays when a source's information is communicated to a destination. A relaying selection technique which saves resources is the Opportunistic Relay Selection (ORS) or Best Relay Selection (BRS) [58]. In ORS, the source either broadcasts or activates exactly one of the available relays, thus saving resources since the relay uses only one channel to transmit to the destination. The selection process involves the exchange of the Channel State Information (CSI) between communicating nodes. After the CSI exchange, a centralized or distributed algorithm activates the best relay to help the sourcedestination communication. Various ORS protocols have been proposed when global CSI e.g., [59], [6o], or partial CSI is available e.g., [61], [62]. A survey on BA relay selection algorithms can be found in [63]. Therein, several relay selection policies are evaluated and classified based on their duplexing capabilities, CSI, transmission strategies, relay mode, and performance metrics.

Cooperative relaying techniques have already greatly affected Device-todevice $\left(\mathrm{D}_{2} \mathrm{D}\right)$ communications in that UEs are acting as relays nodes in future communication networks. Buffering at UEs improves efficiency of cooperation among users since data can be shared in a peer-to-peer fashion thereby avoiding overloading the core network. Reliable $\mathrm{D}_{2} \mathrm{D}$ communication requires constant CSI estimation from the UEs which incurs increased power expenditure. To this end, efficient distributed power control algorithms e.g., [64], [65], have been proposed. Other proposals incorporate mmWave communications to mitigate the interference with the cellular network [66], [67].

Buffer-aided relay selection is ideal for many application scenarios. For example, the highly dynamic topology of $\mathrm{V} 2 \mathrm{~V}$ networks combined with buffering and multi-hop transmissions results in vehicular delay-tolerant network (VDTN) that will exhibit intermittent connectivity and delay as well as asymmetric transmission rates that must be carefully studied [68], [69]. Cooperative relaying can increase the reliability of critical IoT applications of smart grids in which smart meters measure the power consumption demand from the nodes and transmit it to a Data Aggregator Unit (DAU) using wireless broadband access networks. A relay station is used to improve the transmission rate and avoid congestion at the DAU [7o]. 
Furthermore, the increasing number of Machine-to-machine ( $\left.\mathrm{M}_{2} \mathrm{M}\right)$ transmissions covering a broad range of applications such as smart home, smart cities, e-health, etc., requires reliable communication with the optimal allocation of resources. Utilizing relays as data aggregators can induce significant gains in the reliability of networks supporting IoT applications [71]. All in all, the majority of IoT applications requires techniques that provide flexibility in resource allocation and data dissemination. Thus, cooperative relaying can be considered as an enabling technology for the increasingly demanding IoT era.

\subsection{Network Function Virtualization (NFV)}

It has been effective in many applications to use an Operating System (OS) to simulate the existence of several machines on a single physical machine. The concept of virtualization is used to describe technologies for managing computating resources by providing a software abstraction layer between the software and the hardware. Virtualization turns physical resources into logical or virtual ones thereby enabling users, applications, and software above the abstraction layer to use resources without the need of knowing the physical details of the underlying resources.

In order to support multiple operating systems, application developers need to create, manage and support multiple hardware and software platforms, a process that is usually expensive and resource-intensive. A strategy for dealing with this problem is known as hardware virtualization. A virtualization technology allows one physical machine to simultaneously run multiple operating systems or multiple sessions of one single OS. Consequently, a physical machine running virtualization software can host numerous applications even if they run on different operating systems. The host OS can support a number of VMs, each of which offers the services of a particular OS and, in some versions of virtualization, the characteristics of a particular hardware platform.

One solution that enables virtualization is the Virtual Machine Monitor (VMM) or hypervisor. It allows multiple VMs to coexist and share resources of one physical machine. A hypervisor can also consolidate the resources of more physical machines to serve the needs of more VMs. Server consolidation leads to fewer physical servers, more energy efficiency, less need for cooling, fewer network devices, fewer cables, and, hence, it has become a valuable method for saving resources. Nowadays, more virtual servers are being deployed in the world that physical servers and this trend is expected to accelerate. 


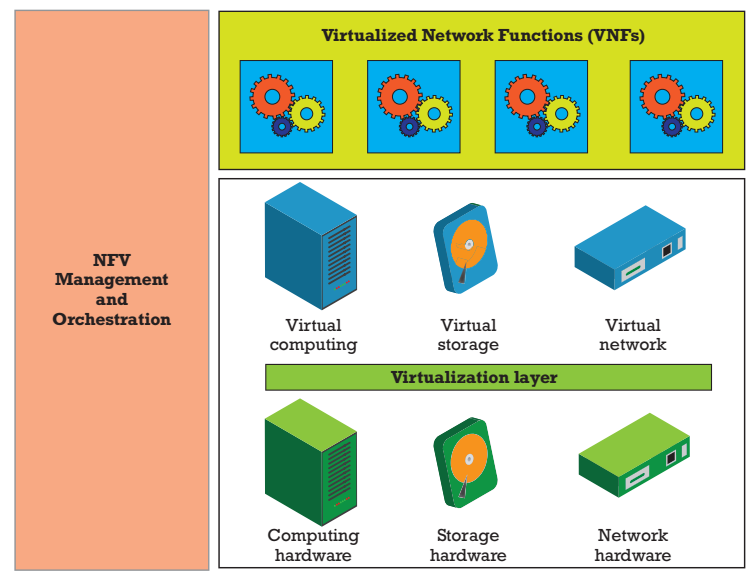

Figure 2.2: An abstract view of the NFV framework.

A more contemporary virtualization approach is known as container virtualization in which a software, known as virtualization container, runs on top of the host OS and provides an execution layer for applications. As a result, the resources needed to run a separate OS for each application (or Virtual Machine (VM)) can be devoted to other operations. Since the containers run on the same OS, they are less resource-intensive compared to hypervisors.

Until recently, the VM technology was being used for application-level server functions such as database servers, web servers, email servers, etc. However, this technology can be equally used to network devices such as routers, switches, and access points. Network Function Virtualization (NFV) decouples network functions such as routing, firewalling, and caching from proprietary/closed hardware platforms and implements them as software ones.

An implementation of a Network Function (NF) that can be deployed on a Virtualized Network Function Infrastructure (VNFI) is called a Virtualized Network Function (VNF). The latter is the building block for creating Network Services (NS) e.g., a monitoring web-service. VNFs are modular and each VNF typically provides limited functionality by itself. However, service providers can define the order of VNFs execuction to achieve the desired functionality. This is refered to as service chaining. The VNFI performs virtualization functions on three categories of devices: computer, storage, and network devices (see Fig. 2.2).

Furthermore, the NFV Management and Orchestration (NFV-MANO) embraces all virtualization-related tasks necessary for the NFV operation. It includes the orchestration and management of physical, or virtual, resources that 
support the NFV infrastructure and the lifecycle management of VNFs. Examples include VNF instance creation and shutdown, service chaining, monitoring, relocation, and monetization.

Compared to traditional networking approaches, a number of benefits can be obtained by employing NFV. First and foremost, reduced CAPEX and OPEX can be realized by exploiting economies of scale, consolidating equipment and reduced network management and control expenses. Secondly, time to launch new network services is reduced and, hence, network operators can seize new market opportunities. Third, a single platform can be used for different applications and users, thereby allowing network operators to share resources among services. Moreover, in a VNFI, services can be scaled up or down on-demand, thereby offering interoperability and flexibility to network operators to address a wide variety of ecosystems, geographical or customer needs as required.

\subsection{Caching}

Caching is mature technique from the domain of operating systems. It refers to the process of storing data in the cache so that future requests for that data can be served faster. The term cache was introduced in computer systems to describe memories with very fast access times but, typically, small capacity due to their increased cost [72]. A small cache memory can significantly improve the system performance by identifying and exploiting correlations in memory access patterns. Later, the idea of caching was applied to the Internet as well [73]. Popular web-pages were replicated in smaller servers (caches) thereby reducing network bandwidth, content access time, and server congestion [74].

The rapid growth in Internet traffic rendered the management of these caches complicated. The need for a technology to monitor and manage interconnected caches led to development of Content Delivery Networks (CDNs). A $\mathrm{CDN}$ replicates popular content in many geographical areas with the intention of saving bandwidth as well as reducing delay by avoiding unnecessary multi-hop transmissions [75]. Research in CDNs investigated where to deploy servers, how much storage capacity to allocate to each server, which files to cache, and how to route files from caches to end-users see e.g., [76]-[79], and the references therein.

Caching has also been applied to improve content delivery in wireless networks as an additional way to improve capacity besides increasing the physical layer transmission rate and densifying the network infrastructure. Replicat- 


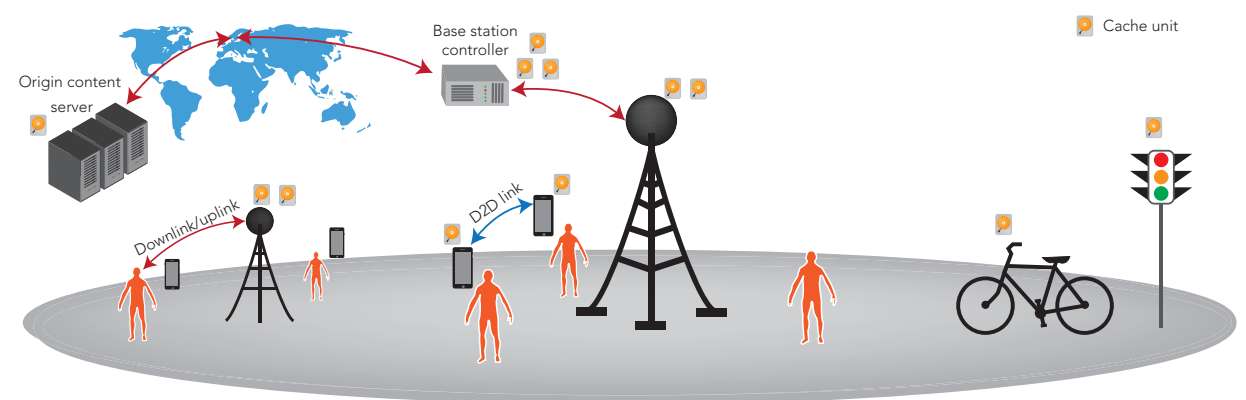

Figure 2.3: An illustration of caching in an IoT environment. Content originated at the content server are cached at the base stations and user devices to offload communicating links.

ing popular reusable content at different parts of the network has been considered. For example: (i) caching at the base station reduces the backhaul load [8o], (ii) caching at the user equipment exploits $\mathrm{D}_{2} \mathrm{D}$ communications [81], and (iii) coded caching accelerates broadcast transmissions [82].

Resource-constrained IoT devices with severe limitations on power, computation, and networking capabilities typically spend a large part of their lifetime in sleep mode and wake up only when they need to exchange data. Thus, energy-efficient operation is crucial for this type of devices. Caching can assist retrieving content even in constrained networks by satisfying data requests from another node that is awake and stores a copy of the requested data [3]. Therefore, whether caching should be enabled in any IoT device or only on powerful nodes should be considered. The work in [83] demonstrates that caching is highly beneficial even when enabled in IoT devices with small capacity. The research community is converging to enable caching as depicted in Fig. 2.3. Storage e.g., memory units, can be installed in gateway routers, base stations, and user devices to offload communicating links.

A cache can typically store a small subset of the files library because of its finite capacity. Thus, caching policies are needed to decide which files are placed into the cache i.e., the cache placement, as well as which files to evict from the cache when the cache is full and a new file should be cached i.e., the cache eviction. Many content placement strategies have been proposed in the literature e.g., caching the Least Frequently Used (LFU) content [8o], caching the Most Popular Content (MPC) [8o], probabilistic caching [84], cooperative caching [85], and geographical caching [86].

A typical performance criterion for a caching policy is the cache hit ratio 
i.e., what percentage of file requests the cache can serve [87]. Earlier research works involve the density of successful receptions [84] as well. More recently, research works considered energy efficiency (or consumption) [88], or the traffic load of the wireless links [89]. The offloading probability is usually optimized to reduce traffic load [90]. Additionally, a considerable amount of contemporary works consider throughput and/or delay. Towards reducing delay, many works mitigate the backhaul or transmission delay under the assumption that traffic or requests are saturated. Works that do not make this assumption, but assume stochastic arrivals have also been published e.g., [91].

The design of a caching system typically involves a model for generating content requests the so-called content popularity model. This approach is much faster than using the actual request traces on the fly. A commonly used model is Independent Reference Model (IRM) because of its simplicity [92]. However, it assumes that content popularity is static which is not true. Time-varying content popularity models have been proven to be more accurate that the IRM in terms of caching performance [8o]. Three time-varying models that have influenced contemporary implementations were proposed in [93].

Since content popularity is time-varying, tracking changes in content popularity is required for the optimization of caching operations. The Least Recently Used (LRU) policy combats the time-varying nature of content popularity, but it works well for multiples of ten, or more, requests per content per day. Wireless networks, however, demand a much smaller number of requests per content per day thereby making fast variations in popularity a difficult problem to track [94]. This necessitates the development of new caching techniques that employ learning methodologies to accurately track the time-varying nature of content popularity. Recently, many approaches have produced notable results towards learning the instantaneous popularity model with no prior assumption on its distribution e.g., learning approaches are employed in [95], [96] and a prediction method is used in [97] while assuming that the popularity evolution is stationary. A recent work that makes no stationarity assumption can be found in [87]. 


\section{Chapter 3}

\section{Mathematical Modeling}

The main approaches for addressing the problems in this dissertation stem from mathematical optimization and queueing theory. In this section, we provide an introduction to basic concepts we used from these mathematical theories. The reader is encouraged to study [98]-[101] for an overview on methods from mathematical optimization and [102]-[105] for resources on queueing theory.

\subsection{Mathematical Optimization}

A general mathematical optimization problem can be formulated as:

$$
\begin{array}{cr}
\text { minimize } & f_{0}(x) \\
\text { subject to } & f_{i}(x) \leq 0, \quad i=1, \ldots, m \\
& h_{i}(x)=0, \quad i=1, \ldots, p
\end{array}
$$

to describe the problem of finding an $x^{*}$, among all possible decision variables $x$, that minimizes the objective function $f_{0}(x)$ and satisfies $m$ inequality $f_{i}(x) \leq 0$ and $p$ equality $h_{i}(x)=0$ constraints. The problem (3.1) is said to be feasible if there exists at least one feasible point and infeasible, otherwise. Moreover, the problem is said to be unbounded if the optimal objective value $f_{0}\left(x^{*}\right)$ is $-\infty$. Optimization problems can be further classified based on the type of the decision variables (continuous, discrete, binary, etc.), the constraints and the objective function (linear, convex, nonlinear, etc.). When the objective and all constraint functions in (3.1) are linear and the variables are continuous, the problem is called a Linear Program (LP). The problem is Non-Linear Problem (NLP) if the 
objective or some constraint in (3.1) is nonlinear. The standard form of an LP problem is w.l.o.g. the following:

$$
\begin{aligned}
\operatorname{minimize} & c^{T} x \\
\text { subject to } & A x=b \\
x & \geq 0
\end{aligned}
$$

where $c$ is the vector of objective coefficients, $c^{T}$ is the transposed vector of $c$, $b$ is a column vector with $m$-dimensions, and $A$ is a matrix with $m$ rows and $n$ columns. The linear constraints $A x=b$ and the set of continuous variables $x \geq 0$ define a feasible region of an LP problem as a polyhedron [100]. If the problem is feasible, the optimal point is an extreme point of the polyhedron. Algorithmic solutions and discussion on LP problems can be found in [98], [100], [106]. Many practical scenarios require decision variables to be integer. In this case, the problem formulation is similar to (3.2) with integer restrictions on the decision variables and the problem is called an Integer Program (IP). In these problems, the optimal point is not an extreme point of a polyhedron as in LPs. Instead, it is a point that yields the optimal value among a finite set of possible solutions. If, additionally, all variables are restricted to be binary i.e., in $\{0,1\}$, then the problem is called a binary integer program (BIP), and mixed integer programming (MIP) if some variables are restricted to be integral.

\subsubsection{Optimization Algorithms}

An LP, IP, or MIP problem formulation is generally advantageous compared to NLP formulations. LP problems can be solved to global optimality by algorithms such as simplex or interior-point methods [107]. In general, integrality restrictions make solving IP and MIP problems much harder compared to LPs. Even though, there are algorithms that solve IP (and MIP) problems to global optimality, they are typically more time-consuming especially for large-scale problem instances. The execution time of IP (and MIP) algorithms are generally exponential to the number of integer variables [106]. Moreover, for these problems, no algorithm that is guaranteed to scale well has appeared so far.

Algorithms for solving optimization problems can be broadly categorized to exact as well as heuristic algorithms. Exact algorithms guarantee global optimality at the expense of possibly exponential time. On the other hand, heuristics sacrifice global optimality for lower time complexity. Interested readers are referred to [108], [109] concerning exact algorithms and heuristics for tackling IP and 
MIP problems. In this thesis, besides mathematical optimization, heuristics algorithms have been applied. We give a brief introduction to the general idea of each one of them below.

\section{Greedy}

Greedy algorithms are one of the simplest and most intuitive heuristics. They iteratively construct solutions until they reach a feasible solution. The algorithm stops once a feasible, and usually suboptimal, solution is obtained. In each iteration, the algorithm makes a choice that is locally best. Thus, greedy algorithms do not guarantee global optimality. However, greedy algorithms are usually very easy to implement and can provide high quality solutions. Consequently, they can act as algorithms for finding feasible solutions fast as part of more complicated algorithms such as local or Tabu search.

\section{Lagrangian Relaxation}

Relaxation is one algorithmic approach to tackle hard optimization problems. The idea is to relax i.e., remove, some of the complicating constraints of the hard problem in the hope of "relaxing" the hard problem to an easier one. The relaxation of the original problem usually leads to a lower-bound (or upperbound) for a minimization (or maximization) problem. In general, removing a constraint may lead to weak bounds i.e., far away from the original problem's optimum value.

The basic idea is to take the constraints in (3.1) into account by augmenting the objective function with a weighted sum of the constraint functions. For example, if we relax the inequality constraints $h_{i}(x)=0, i=1, \ldots, p$, the Lagrangian subproblem of the original problem (3.1) is formulated as follows:

$$
\begin{array}{rr}
\text { minimize } & f_{0}(x)+\sum_{i=1}^{P} \lambda_{i} h_{i}(x) \\
\text { subject to } & f_{i}(x) \leq 0, \quad i=1, \ldots, m,
\end{array}
$$

where $\lambda_{i}$ is the Lagrangian multiplier (or dual variable) associated the $i$-th equality constraint $h_{i}(x)=0$ of the original problem. Similarly, we can relax any inequality constraint $f_{i}(x) \leq 0$.

The objective function of problem (3.3) defined as:

$$
L(x, \lambda)=f_{0}(x)+\sum_{i=1}^{P} \lambda_{i} h_{i}(x)
$$


is called the Lagrangian function. The best lower bound is given by solving the so-called Lagrangian dual problem:

$$
g(\lambda)=\inf _{x} L(x, \lambda)=\inf _{x}\left(f_{0}(x)+\sum_{i=1}^{P} \lambda_{i} h_{i}(x)\right) .
$$

The dual function yields lower bounds on the optimal value $Z^{*}$ of the problem (3.1). Thus, for any $\lambda \geq 0$ and any feasible point $\bar{x}$ of the original problem, the following inequalities hold:

$$
g(\lambda) \leq Z^{*} \leq f_{0}(\bar{x})
$$

Besides the methods mentioned above. there are numerous other heuristics such as local and tabu search [110], [111], simulated annealing [112], genetic algorithms [113], etc. The choice of heuristics depends on the structure of the problem and is generally not trivial.

\subsection{Queueing Theory}

Queueing theory is the mathematical study of queues or waiting lines. Queues flourish in practical situations. The earlier uses of queueing theory was in designing a telephone system. Numerous applications have appeared in seemingly diverse areas such as traffic control, time-shared computer operating systems, industrial engineering, telecommunications, etc. In this section, we present elements of queueing theory that we have used in this dissertation.

\subsubsection{Queueing Systems}

Items in a queueing system randomly arrive at an average rate of $\lambda$. Upon arrival, they are served without delay if there are available servers, or queued until it is their turn to be served. Once served, they leave the system. A queueing system requires the specification of three components: (i) the arrival process, (ii) the service process, and (iii) the service discipline e.g., first in first out (FIFO), also known as first come first served (FCFS).

\subsubsection{The discrete time Birth-Death (BD) Process}

In Birth-Death (BD) processes, a single birth (or item arrival) can occur at anytime and the death rate depends on the number of units in the system. Thus, a 
$\mathrm{BD}$ process can only increase or decrease the number in the system by, at most, one unit at a time.

In the discrete time version, we assume the birth process is a Bernoulli process and the death process follows a geometric distribution. We state the problem formally as a Markov chain. Let $X_{n}$ be the number of units in the systems, including the ones being processed, at time $n$. Let $D\left(X_{n}\right)$ be the number of service completion at time $n$ when there are $X_{n}$ items in the system and $A\left(X_{n}\right)$ be the number of arrivals at time $n$ when there are $X_{n}$ items in the system. It is clear that, in BD processes, $A\left(X_{n}\right) \in\{0,1\}$ and $D\left(X_{n}\right) \in\{0,1\}$. Moreover, $D(0)=0$. The stochastic process $\left\{X_{n}, n=0,1,2, \ldots\right\}, X_{n} \in\{0,1,2,3, \ldots\}$, is a Discrete Time Markov Chain (DTMC) with the following relationship:

$$
X_{n+1}=\max \left\{0, X_{n}-D\left(X_{n}\right)\right\}+A\left(X_{n}\right) .
$$

The DTMC representing this BD process is discussed in the next section.

Let $a_{i}=\{$ "The probability of birth occurs when there are $\mathrm{i} \geq 0$ items in the system." $\}$ and $\bar{a}_{i}=1-a_{i}$. Similarly, define $b_{i}=\{$ "The probability that a death occurs when there are $i \geq 1$ items in the system" $\}$, and $\overline{b_{i}}=1-b_{i}$. We assume that $b_{0}=0$.

Let $\left\{X_{n}, n \geq 0\right\}$ be the Markov chain's state space, then the transition matrix of this chain is given as:

$$
\mathbf{P}=\left(\begin{array}{ccccc}
\overline{a_{0}} & a_{0} & & & \\
\overline{a_{1}} b_{1} & \overline{a_{1}} \overline{b_{1}}+a_{1} b_{1} & a_{1} \overline{b_{1}} & & \\
& \overline{a_{2}} b_{2} & \overline{a_{2}} \overline{b_{2}}+a_{2} b_{2} & a_{2} \overline{b_{2}} & \\
& & \ddots & \ddots & \ddots
\end{array}\right) .
$$

If we define $x_{i}^{(n)}=\operatorname{Pr}\left\{X_{n}=i\right\}$ as the probability that there are $i$ items in the system at time $n$, and $\mathbf{x}^{(n)}=\left[x_{0}^{(n)}, x_{1}^{(n)}, \ldots\right]$, then we have:

$$
\mathbf{x}^{(n+1)}=\mathbf{x}^{(n)} \mathbf{P}
$$

If $\mathbf{P}$ is irreducible and positive recurrent, then there exists an invariant vector, which is also equivalent to the limiting distribution: $\mathbf{x}=\lim _{n \rightarrow \infty} \mathbf{x}^{(n)}$ and given by:

$$
\mathbf{x} \mathbf{P}=\mathbf{x}
$$

under the normalizing condition that $x^{T} \mathbb{1}=1$. 


\subsubsection{Geo/Geo/1 Queues}

In this section, we study a queuing model where we have arrivals according to the Bernoulli process and the service time following a geometric distribution. When items arrival follow the Bernoulli process, their inter-arrival times follow the geometric distribution. This system is called a Geo/Geo/1 queueing system. An example application off this queueing model in telecommunications is a system in which packets arrive at a single server e.g., a router, according to the Bernoulli process.

We consider the case in which $a_{i}=a, \forall i \geq 0$ and $b_{i}=b, \forall i \geq 1$. The transition matrix $P$ becomes:

$$
\mathbf{P}=\left(\begin{array}{ccccc}
\bar{a} & a & & & \\
\bar{a} b & \bar{a} \bar{b}+a b & a \bar{b} & & \\
& \bar{a} b & \bar{a} \bar{b}+a b & a \bar{b} & \\
& & \ddots & \ddots & \ddots
\end{array}\right) .
$$

Several methods can be used to analyze this Markov chain [102].

\subsubsection{Geo/Geo/1/K Queues}

$\mathrm{Geo} / \mathrm{Geo} / 1 / \mathrm{K}$ systems are the same as $\mathrm{Geo} / \mathrm{Geo} / 1$ systems but with a finite buffer $K<\infty$. Hence, when an item arrives to the full buffer i.e., $K$ items are waiting in the buffer, the arriving item is dropped. Other dropping policies can also be applied e.g., an arriving item is accepted and the item at the head of the queue is dropped. This system is a special case of the BD process or of the $\mathrm{Geo} / \mathrm{Geo} / 1$ system.

We consider the case in which $a_{i}=a, 0 \leq i \leq K, \forall i \geq K+1$ and $b_{i}=b, \forall i \geq 1$. Hence, the transition matrix $P$ becomes:

$$
\mathbf{P}=\left(\begin{array}{ccccc}
\bar{a} & a & & & \\
\bar{a} b & \bar{a} \bar{b}+a b & a \bar{b} & & \\
& \bar{a} b & \bar{a} \bar{b}+a b & a \bar{b} & \\
& & \ddots & \ddots & \ddots \\
& & & \bar{a} & \bar{a} \bar{b}+a
\end{array}\right)
$$

thereby forming a finite space DTMC. 


\section{Chapter 4}

\section{Contributions}

This dissertation stems from our investigations on cooperation and resource allocation towards optimizing the performance of IoT wireless systems. The research topics cover allocation of IoT resources, throughput and delay analysis of IoT systems with relay nodes, scheduling VNFs on virtual machines, and exploiting caching in IoT systems that serve two types of network traffic. The scope of the thesis is formed by the mathematical formulation of the studied cooperation and resource allocation problems, performance analysis of the systems metrics, algorithmic development and computational complexity, as well as numerical results.

The thesis includes five research papers. The main ideas were the result of discussions among all authors. In paper I, the dissertation author partly contributed to the system model, designed and implemented the simulation part, and wrote the paper. The author of this dissertation has contributed to papers II-V as the first author working on the development of the optimization and queueing theory formulations, theoretical analysis and implementation of algorithms, the theorem proof, the simulation and numerical results along with the writing of the papers. 


\subsection{Summary of papers}

We provide a summary of each paper in the following part.

\section{Paper I: Allocation of Heterogeneous Resources of an IoT Device to} Flexible Services co-authored with V. Angelakis, N. Pappas, E. Fitzgerald, and D. Yuan. This paper has been published in IEEE Internet of Things Journal, vol. 3, no. 5, October 2016.

IoT devices can offer their resources in the form of multiple heterogeneous network interfaces. A massive amount of services may require whole or in part the interfaces' resources. Every interface can serve different kind of resources associated with them (e.g., computation, data rate, etc.). We assume that services are flexible to split their allocations on multiple interfaces to satisfy their demands. Herein, we provide a Mixed Integer linear programming (MILP) mathematical formulation of allocating services to interfaces with heterogeneous resources in one or more rounds. We prove that the problem is the NP-complete and develop two algorithms to approximate the optimal solution for large instances. The first algorithm allocates the most demanding service requirements first by considering the average cost of interfaces' resources. The second algorithm first computes the demands' resource shares and allocates the most demanding of them first by choosing randomly among equally demanding shares.

The numerical results demonstrate the role of the activation cost on the services' splits among interfaces. We also investigate the effect of the number of rounds on the total costs based on two approaches: (i) using the minimum number of rounds to achieve feasibility, and (ii) using as many rounds as necessary to achieve the minimum total cost at the expense of using more rounds. The difference of the cost between the two approaches of the two bounds (minimum rounds vs. minimum cost) is more profound when the number of services is increased.

Parts of the paper have been accepted for publication in the following conference:

- V. Angelakis, I. Avgouleas, N. Pappas, and D. Yuan., "Flexible allocation of heterogeneous resources to services on an IoT device”, in IEEE Conference on Computer Communications Workshops (INFOCOM WKSHPS),pp. 99-100, April 2015. 


\section{Paper II: Virtual Network Functions Scheduling under Delay-Weighted} Pricing, co-authored with D. Yuan, N. Pappas, and V. Angelakis. This paper is published in IEEE Networking Letters, Aug. 2019.

Network Function Virtualization (NFV) is a network architecture framework that decouples network functionalities from dedicated hardware and implements them as Virtual Network Functions (VNFs). Traditional network functions such as firewalling, routing, etc., can be virtualized by software implementations. Consequently, general purpose hardware can serve the same network demands and significant reductions in the operating (OPEX) and capital expenses (CAPEX) can be realized.

NFV allows network operators to utilize one or more VNFs to implement a Network Service (NS) e.g., caching popular video streams. Towards that end, two main problems call for addressing: (i) the so-called VNF chain i.e., the order by which VNFs execute, and (ii) the allocation of the VNF chain in the Network Functions Virtualization Infrastructure (NFVI) [114]-[116].

Herein, we consider a NS comprising of multiple VNF instances demanding allocation on virtual machines (VMs) of a High Volume Server (HVS). We formulate the problem as a mixed integer linear programming (MILP) one by taking into account the number of VMs, the VNF instances, as well as the VNFs' completion time tolerance with the intention of reducing the VMs activation and VNFs' serving cost. To the best of our knowledge, this solution approach has not been examined so far. We prove that the problem is NP-complete. A subgradient optimization algorithm with low complexity is designed based on the MILP formulation. Additionally, we provide numerical results to examine the behavior of our algorithm in comparison to the MILP optimal solution. The results demonstrate the effectiveness of our algorithm in minimizing the VM activations and VNF serving cost.

Parts of the paper were accepted for publication and presented in the following conference:

- I. Avgouleas, N. Pappas, and V. Angelakis "Scheduling Services on an IoT Device Under Time-Weighted Pricing", in IEEE International Symposium on Personal, Indoor and Mobile Radio Communications (PIMRC) Workshop on Communication for Networked Smart Cities (CORNER), October 2017. 


\section{Paper III: Probabilistic Cooperation of a Full-Duplex Relay in Random}

Access Networks, co-authored with N. Pappas, D. Yuan, and V. Angelakis. This paper has been published in IEEE Access, vol. 5, pp. 7394-7404, Dec. 2016.

In this work, we consider a wireless system with multiple users attempting to transmit their packets to a common destination node. The wireless channel is assumed to be random access and users' transmissions are assisted by a FullDuplex (FD) relay node. The latter has independent activation capabilities for the receiver and the transmitter, namely, they are activated with some probability. Furthermore, we assume time is slotted and that a packet transmission takes exactly one time-slot. Acknowledgements of successful transmissions are assumed instantaneous and error-free. We also assume multiple packet reception (MPR) for the receiving nodes. If a user's transmission to the destination fails, the relay queues the failed packet in order to forward it to the destination in a future time slot. Users are assumed to have always packets to send. The relay does not generate its own packets, since its sole purpose is to support users' traffic.

The paper gives insights into how to set the parameters of a FD relay node to maximize the system throughput. We provide analytical expressions for the performance of the relay queue as well as the average queue size. We also extract conditions for stability of the relay's queue as functions of the activation probability of the relay's receiver and the transmitter, the transmission probabilities, the self-interference cancellation coefficient, and the links' outage probabilities. Additionally, we investigate the effect of the parameters of the relay node on the per-user and the network-wide throughput. The proposed optimization formulation opts for maximizing throughput, while guaranteeing the queue's stability i.e., guaranteeing finite packet delay.

Our numerical evaluations provide the optimal values by which the relay's receiver and transmitter should be activated to maximize throughput, whilst the relay's queue is stable and demonstrate the effect of self-interference on the peruser and network-wide throughput. In case the link Signal-to-Interference-plusNoise Ratio (SINR) minimal threshold is low and the relay operates in FD mode, it is advantageous to deactivate both the receiver and the transmitter when a moderate number of users is transmitting. Instead, when the relay operates in Half-Duplex (HD) for the same SINR values, the results show that its receiver should be deactivated when a higher number of users is transmitting to achieve optimality.

Parts and minor variations of the paper were accepted for publication and pre- 
sented in the following conference:

- I. Avgouleas, N. Pappas, and V. Angelakis, "Cooperative Wireless Networking with Probabilistic On/Off Relaying," in Proc. of IEEE 81st Vehicular Technology Conference (VTC Spring), pp. 1-5, May 2015.

Paper IV: Wireless Caching Helper System with Heterogeneous Traffic and Random Availability, co-authored with N. Pappas and V. Angelakis. This paper was submitted to IEEE Access on July 2019.

Multimedia content e.g., music or video, streaming from Internet-based sources emerges as one of the most demanded services. In order to mitigate excessive traffic caused by excessive multimedia content transmission, many networked architectures (e.g., small cells, femtocells, etc.) have been proposed to offload such traffic to the nearest access point i.e., the so-called "helper". Wireless caching helpers are typically gateway routers, base stations, and user devices that replicate popular content to avoid unnecessary multihop retransmissions and, hence, increase throughput and decrease delay as a byproduct of decreasing the distance between communicating nodes.

In this paper, we study a wireless system in which traffic is distinguished between cacheable and non-cacheable. A user with cache storage requests cacheable content from a data center connected with a base station. Two wireless nodes within the proximity of the user exchange non-cacheable content and have cache storage capabilities. Therefore, they can act as caching helpers for the user by serving its requests for cacheable content. Files not available at the helpers can be fetched by data center. Additionally, the source helper is equipped with an infinite queue whose role is to save the excessive traffic with the intention of transmitting it to the destination helper in a subsequent time slot.

We formulate the system throughput and the average delay experienced by the user as well as demonstrate, by means of numerical results, how they are affected by the packet arrival rate at the source helper, the availability of caching helpers, the parameters of the caches, and the request rate of the user. Our theoretical and numerical results provide insights concerning the system throughput and the delay behavior of wireless systems serving both cacheable and non-cacheable content with the assistance of multiple randomly available caching helpers.

Parts of the paper were accepted for publication and presented in the following conference: 
- I. Avgouleas, N. Pappas, and V. Angelakis, "Performance Evaluation of Wireless Caching Helper Systems", in the 15th IEEE international Conference on Wireless and Mobile Computing, Networking and Communications (WiMob), October 2019.

\section{Paper V: Cacheable and Non-Cacheable Traffic Interplay in a} Relay-Assisted Wireless Network, co-authored with N. Pappas and V. Angelakis. This paper has been submitted to IEEE International Conference on Communications (ICC) 2020.

The use of caching in the recent past has been successful in reducing cellular traffic and delay as well as increasing network throughput and reliability. Cacheenabled ${ }_{5} \mathrm{G}$ wireless systems and future network architectures will benefit from caching in terms of reduced costs for the network infrastructure and improved quality of service to end users.

In this paper, we study a discrete-time wireless system that serves both cacheable and non-cacheable traffic with the assistance of a relay node. The latter has storage capabilities to accommodate the needs of both types of traffic. In each time slot, a wireless node attempts transmitting non-cacheable traffic to a destination node and another user requests a cached file from external resources i.e., the relay node and a base station, in case of a relay's cache miss or the relay is unavailable for caching. The base station is connected with a data center that contains the cached files library and is available to assist requests for cached files with some probability.

We investigate how assigning the storage capacity to cacheable and noncacheable traffic affects the system throughput. Our numerical results provide useful insights into the system throughput e.g., that it is not always beneficial for the system throughput to increase the rate by which the non-cacheable traffic is transmitted, or that it is not necessarily beneficial to increase the storage capacity allocated for the non-cacheable traffic to realize better throughput at the non-cacheable destination node. 


\section{Bibliography}

[1] A. Al-Fuqaha, M. Guizani, M. Mohammadi, M. Aledhari, and M. Ayyash, "Internet of Things: A Survey on Enabling Technologies, Protocols, and Applications", IEEE Communications Surveys Tutorials, vol. 17, (4), pp. 2347-2376, 2015.

[2] A. Whitmore, A. Agarwal, and L. Da Xu, "The Internet of Things-A survey of topics and trends", Information Systems Frontiers, vol. 17, (2), pp. 261-274, Apr. 2015.

[3] M. Amadeo, C. Campolo, J. Quevedo, D. Corujo, A. Molinaro, A. Iera, R. L. Aguiar, and A. V. Vasilakos, "Information-Centric Networking for the Internet of Things: Challenges and Opportunities", IEEE Network, vol. 30, (2), pp. 92-100, 2016.

[4] H. C. Pöhls, V. Angelakis, S. Suppan, K. Fischer, G. Oikonomou, E. Z. Tragos, Rodrigo Diaz Rodriguez, and T. Mouroutis, "RERUM: Building a reliable IoT upon privacy- and security- enabled smart objects", IEEE Wireless Communications and Networking Conference Workshops (WCNCW), pp. 122-127, Apr. 2014.

[5] M. Nitti, V. Pilloni, G. Colistra, and L. Atzori, "The Virtual Object as a Major Element of the Internet of Things: A Survey", IEEE Communications Surveys Tutorials, vol. 18, (2), pp. 1228-1240, 2016.

[6] F. Mattern and C. Floerkemeier, "From the Internet of Computers to the Internet of Things”, Informatik-Spektrum, vol. 33, pp. 242-259, Sep. 2010.

[7] Y. Chen and T. Kunz, "Performance evaluation of IoT protocols under a constrained wireless access network", International Conference on Selected Topics in Mobile Wireless Networking (MoWNeT), pp. 1-7, Apr. 2016. 
[8] Z. Shelby, K. Hartke, and C. Bormann, The Constrained Application Protocol (CoAP), RFC 7252, Jun. 2014.

[9] D. Thangavel, X. Ma, A. Valera, H. Tan, and C. K. Tan, "Performance evaluation of MQTT and CoAP via a common middleware", IEEE Ninth International Conference on Intelligent Sensors, Sensor Networks and Information Processing (ISSNIP), pp. 1-6, Apr. 2014.

[10] R. Want, B. N. Schilit, and S. Jenson, "Enabling the Internet of Things", Computer, vol. 48, (1), pp. 28-35, Jan. 2015.

[11] S. K. Datta, R. P. F. Da Costa, and C. Bonnet, "Resource discovery in Internet of Things: Current trends and future standardization aspects", 2015 IEEE 2nd World Forum on Internet of Things (WF-IoT), pp. 542-547, Dec. 2015.

[12] M. Agiwal, A. Roy, and N. Saxena, "Next Generation 5G Wireless Networks: A Comprehensive Survey", IEEE Communications Surveys Tutorials, vol. 18, (3), pp. 1617-1655, Feb. 2016.

[13] L. Li, S. Li, and S. Zhao, "QoS-Aware Scheduling of Services-Oriented Internet of Things", IEEE Transactions on Industrial Informatics, vol. 10, (2), pp. 1497-1505, May 2014.

[14] I. F. Akyildiz, Jiang Xie, and S. Mohanty, "A survey of mobility management in next-generation all-IP-based wireless systems”, IEEE Wireless Communications, vol. 11, (4), pp. 16-28, Aug. 2004.

[15] M. Zorzi, A. Gluhak, S. Lange, and A. Bassi, "From today's INTRAnet of things to a future INTERnet of things: a wireless- and mobility-related view”, IEEE Wireless Communications, vol. 17, (6), pp. 44-51, Dec. 2010.

[16] M. Lauridsen, L. C. Gimenez, I. Rodriguez, T. B. Sorensen, and P. Mogensen, "From LTE to $5 \mathrm{G}$ for Connected Mobility", IEEE Communications Magazine, vol. 55, (3), pp. 156-162, Mar. 2017.

[17] T. Kramp, R. Kranenburg, and S. Lange, Introduction to the Internet of Things. Sep. 2013.

[18] L. Georgiadis, M. Neely, and L. Tassiulas, Resource Allocation and Cross Layer Control in Wireless Networks (Foundations and Trends in Networking, V. 1, No. 1). Hanover, MA, USA: Now Publishers Inc., 2006. 
[19] F. Boccardi, R. W. Heath, A. Lozano, T. L. Marzetta, and P. Popovski, "Five disruptive technology directions for 5G", IEEE Communications Magazine, vol. 52, (2), pp. 74-80, Feb. 2014.

[20] L. Atzori, A. Iera, and G. Morabito, "The Internet of Things: A Survey", Comput. Netw., vol. 54, (15), pp. 2787-2805, Oct. 2010.

[21] B. Kantarci and H. T. Mouftah, "Sensing services in cloud-centric Internet of Things: A survey, taxonomy and challenges", IEEE International Conference on Communication Workshop (ICCW), pp. 1865-1870, Jun. 2015.

[22] R. Boisguene, S. Tseng, C. Huang, and P. Lin, "A survey on NB-IoT downlink scheduling: Issues and potential solutions", IEEE International Wireless Communications and Mobile Computing Conference (IWCMC), pp. 547-551, Jun. 2017.

[23] Huawei, "Huawei NB-IoT enabling new business opportunities", Huawei Tech. Rep., 2016.

[24] Ericsson, "Cellular Networks of massive IoT", Ericsson Tech. Rep., Jan. 2016.

[25] A. Augustin, J. Yi, T. Clausen, and W. M. Townsley, "A Study of LoRa: Long Range \& Low Power Networks for the Internet of Things”, Sensors, vol. 16, (9), 2016.

[26] S. Chacko and M. D. Job, "Security mechanisms and vulnerabilities in LPWAN, IOP publishing”, IOP Conference Series: Materials Science and Engineering, vol. 396, pp. 012-027, Aug. 2018.

[27] M. J. Neely, "Optimal Backpressure Routing for Wireless Networks with Multi-Receiver Diversity”, IEEE Annual Conference on Information Sciences and Systems, pp. 18-25, Mar. 2006.

[28] M. Alresaini, K. Wright, B. Krishnamachari, and M. J. Neely, "Backpressure Delay Enhancement for Encounter-Based Mobile Networks While Sustaining Throughput Optimality", IEEE/ACM Transactions on Networking, vol. 24, (2), pp. 1196-1208, Apr. 2016.

[29] B. Mostafa, A. Benslimane, M. Saleh, S. Kassem, and M. Molnar, "An Energy-Efficient Multiobjective Scheduling Model for Monitoring in In- 
ternet of Things", IEEE Internet of Things fournal, vol. 5, (3), pp. 1727-1738, Jun. 2018.

[30] C. Liaskos, X. Dimitropoulos, and L. Tassiulas, "Backpressure on the Backbone: A Lightweight, Non-Intrusive Traffic Engineering Approach”, IEEE Transactions on Network and Service Management, vol. 14, (1), pp. 176-190, Mar. 2017.

[31] M. Awais, A. Mateen, Z. A. Khan, and N. Javaid, "A Survey on Multi-hop Routing Protocols for Efficient Resource Allocation in IoTs", 2018 Fifth HCT Information Technology Trends (ITT), pp. 159-164, Nov. 2018.

[32] C. Fischione, "An Introduction to Wireless Sensor Networks”, Swedish Communication Technologies Workshop (Swe-CTW 2014), Sep. 2014.

[33] R. Minerva, A. Biru, and D. Rotondi. (2015). Towards a definition of the Internet of Things (IoT), [Online]. Available: https://iot.ieee.org/ definition.html.

[34] L. A. DaSilva, "Pricing for QoS-enabled networks: A survey", IEEE Communications Surveys Tutorials, vol. 3, (2), pp. 2-8, Feb. 2000.

[35] F. Wang and J. Liu, "Networked Wireless Sensor Data Collection: Issues, Challenges, and Approaches", IEEE Communications Surveys Tutorials, vol. 13, (4), pp. 673-687, Apr. 2011.

[36] C. A. Gizelis and D. D. Vergados, "A Survey of Pricing Schemes in Wireless Networks”, IEEE Communications Surveys Tutorials, vol. 13, (1), pp. 126145, Jan. 2011.

[37] S. Ehsan and B. Hamdaoui, "A Survey on Energy-Efficient Routing Techniques with QoS Assurances for Wireless Multimedia Sensor Networks", IEEE Communications Surveys Tutorials, vol. 14, (2), pp. 265-278, Feb. 2012.

[38] E. Borgia, "The Internet of Things vision: Key features, applications and open issues”, Computer Communications, vol. 54, pp. 1-31, 2014.

[39] L. Chen, Performance Engineering of Mobile Broadband. Capacity Analysis, Cellular Network Optimization, and Design of In-Building Solutions. Ser. Linköping Studies in Science and Technology. Dissertations: 1504. Department of Science and Technology, Linköping University, 2013. 
[40] A. Capone, L. Chen, S. Gualandi, and D. Yuan, "A New Computational Approach for Maximum Link Activation in Wireless Networks under the SINR Model", IEEE Transactions on Wireless Communications, vol. 10, (5), pp. 1368-1372, May 2011.

[41] A. Capone, I. Filippini, S. Gualandi, and D. Yuan, "Resource Optimization in Multiradio Multichannel Wireless Mesh Networks (Ch.7)", Mobile Ad Hoc Networking, John Wiley \& Sons, Ltd, pp. 239-274, 2013.

[42] A. Pantelidou and A. Ephremides, "The scheduling problem in wireless networks", Journal of Communications and Networks, vol. 11, (5), pp. 489499, Oct. 2009.

[43] Q. He, A Comprehensive Analysis of Optimal Link Scheduling for Emptying a Wireless Network. Ser. Linköping Studies in Science and Technology. Dissertations: 1786. Department of Science and Technology, Linköping University, 2016.

[44] N. C. Luong, D. T. Hoang, P. Wang, D. Niyato, D. I. Kim, and Z. Han, "Data Collection and Wireless Communication in Internet of Things (IoT)", IEEE Communications Surveys Tutorials, vol. 18, (4), pp. 2546-2590, 2016.

[45] G. Kramer, I. Marić, and R. D. Yates, "Cooperative Communications", Found. Trends Netw., vol. 1, (3), pp. 271-425, Aug. 2006.

[46] N. Pappas, A. Traganitis, and A. Ephremides, "Stability and Performance Issues of a Relay Assisted Multiple Access Scheme”, IEEE Global Telecommunications Conference (GLOBECOM), pp. 1-5, Dec. 2010.

[47] A. K. Sadek, K. J. R. Liu, and A. Ephremides, "Cognitive multiple access via cooperation: Protocol design and performance analysis", IEEE Transactions on Information Theory, vol. 53, (10), pp. 3677-3696, Oct. 2007.

[48] N. Pappas, M. Kountouris, J. Jeonz, A. Ephremides, and A. Traganitisy, "Network-level cooperation in energy harvesting wireless networks", IEEE Global Conference on Signal and Information Processing, pp. 383-386, Dec. 2013.

[49] O. Simeone, Y. Bar-Ness, and U. Spagnolini, "Stable Throughput of Cognitive Radios With and Without Relaying Capability", IEEE Transactions on Communications, vol. 55, (12), pp. 2351-2360, Dec. 2007. 
[50] B. Rong and A. Ephremides, "Protocol-level cooperation in wireless networks: Stable throughput and delay analysis", 7th International Symposium on Modeling and Optimization in Mobile, Ad Hoc, and Wireless Networks, pp. 1-10, Oct. 2009.

[51] N. Pappas, A. Ephremides, and A. Traganitis, "Relay-assisted multiple access with multi-packet reception capability and simultaneous transmission and reception", IEEE Information Theory Workshop, pp. 578-582, Oct. 2011.

[52] E. Dahlman, S. Parkvall, and J. Sköld, "Chapter 18 - Relaying", 4G LTEAdvanced Pro and The Road to 5G, 3rd ed., Academic Press, pp. 403-419, 2016.

[53] Y. Yang, H. Hu, J. Xu, and G. Mao, "Relay technologies for WiMax and LTE-advanced mobile systems", IEEE Communications Magazine, vol. 47, (10), pp. 100-105, Oct. 2009.

[54] K. Loa, C. Wu, S. Sheu, Y. Yuan, M. Chion, D. Huo, and L. Xu, "IMTadvanced relay standards [WiMAX/LTE Update]", IEEE Communications Magazine, vol. 48, (8), pp. 40-48, Aug. 2010.

[55] C. Hoymann, W. Chen, J. Montojo, A. Golitschek, C. Koutsimanis, and X. Shen, "Relaying operation in 3GPP LTE: challenges and solutions", IEEE Communications Magazine, vol. 50, (2), pp. 156-162, Feb. 2012.

[56] N. Pappas, J. Jeon, A. Ephremides, and A. Traganitis, "Wireless networklevel partial relay cooperation", IEEE International Symposium on Information Theory Proceedings, pp. 1122-1126, Jul. 2012.

[57] N. Zlatanov, A. Ikhlef, T. Islam, and R. Schober, "Buffer-aided cooperative communications: opportunities and challenges", IEEE Communications Magazine, vol. 52, (4), pp. 146-153, Apr. 2014.

[58] X. Zhang, Z. Yan, Y. Gao, and W. Wang, "On the study of outage performance for cognitive relay networks (crn) with the nth best-relay selection in rayleigh-fading channels", IEEE Wireless Communications Letters, vol. 2, (1), pp. 110-113, Feb. 2013.

[59] A. Bletsas, H. Shin, and M. Z. Win, "Cooperative communications with outage-optimal opportunistic relaying", IEEE Transactions on Wireless Communications, vol. 6, (9), pp. 3450-3460, Sep. 2007. 
[60] D. S. Michalopoulos and G. K. Karagiannidis, "Performance analysis of single relay selection in rayleigh fading”, IEEE Transactions on Wireless Communications, vol. 7, (10), pp. 3718-3724, Oct. 2008.

[61] D. S. Michalopoulos, A. S. Lioumpas, G. K. Karagiannidis, and R. Schober, "Selective Cooperative Relaying over Time-Varying Channels", IEEE Transactions on Communications, vol. 58, (8), pp. 2402-2412, Aug. 2010.

[62] D. S. Michalopoulos, H. A. Suraweera, G. K. Karagiannidis, and R. Schober, "Amplify-and-Forward Relay Selection with Outdated Channel Estimates”, IEEE Transactions on Communications, vol. 60, (5), pp. 12781290, May 2012.

[63] N. Nomikos, T. Charalambous, I. Krikidis, D. N. Skoutas, D. Vouyioukas, M. Johansson, and C. Skianis, "A Survey on Buffer-Aided Relay Selection", IEEE Communications Surveys Tutorials, vol. 18, (2), pp. 1073-1097, Dec. 2015.

[64] G. Fodor, D. D. Penda, M. Belleschi, M. Johansson, and A. Abrardo, "A comparative study of power control approaches for device-to-device communications", 2013 IEEE International Conference on Communications (ICC), pp. 6008-6013, Jun. 2013.

[65] N. Reider and G. Fodor, "A distributed power control and mode selection algorithm for D2D communications", EURASIP fournal on Wireless Communications and Networking, vol. 2012, Aug. 2012.

[66] J. Qiao, X. S. Shen, J. W. Mark, Q. Shen, Y. He, and L. Lei, "Enabling deviceto-device communications in millimeter-wave $5 \mathrm{G}$ cellular networks", IEEE Communications Magazine, vol. 53, (1), pp. 209-215, Jan. 2015.

[67] Y. Xu, H. Shokri-Ghadikolaei, and C. Fischione, "Distributed Association and Relaying With Fairness in Millimeter Wave Networks", IEEE Transactions on Wireless Communications, vol. 15, (12), pp. 7955-7970, Dec. 2016.

[68] T. Petrov, M. Dado, K. E. Ambrosch, and P. Holečko, "Experimental topology for V2V communication based on Internet of Things", 2016 ELEKTRO, pp. 72-76, May 2016.

[69] J. N. G. Isento, J. J.P. C. Rodrigues, J. A.F. F. Dias, M. C. G. Paula, and A. Vinel, "Vehicular Delay-Tolerant Networks? A Novel Solution for Vehic- 
ular Communications", IEEE Intelligent Transportation Systems Magazine, vol. 5, (4), pp. 10-19, Oct. 2013.

[70] D. Niyato and P. Wang, "Cooperative Transmission for Meter Data Collection in Smart Grid", IEEE Communications Magazine, vol. 50, (4), pp. 9097, Apr. 2012.

[71] N. Pappas, I. Dimitriou, and Z. Chen, "Network-Level Cooperation in Random Access IoT Networks with Aggregators", the 30th International Teletraffic Congress (ITC 30), vol. 01, pp. 245-253, Sep. 2018.

[72] L. A. Belady, "A study of replacement algorithms for a virtual-storage computer”, IBM Systems fournal, vol. 5, (2), pp. 78-101, 1966.

[73] Lili Qiu, V. N. Padmanabhan, and G. M. Voelker, "On the placement of Web server replicas”, vol. 3, 1587-1596 vol.3, Apr. 2001.

[74] T. Kelly and D. Reeves, "Optimal Web Cache Sizing: Scalable Methods for Exact Solutions”, Comput. Commun., vol. 24, (2), pp. 163-173, Feb. 2001.

[75] G. S. Paschos, G. Iosifidis, M. Tao, D. Towsley, and G. Caire, "The Role of Caching in Future Communication Systems and Networks", IEEE Journal on Selected Areas in Communications, vol. 36, (6), pp. 1111-1125, Mar. 2018.

[76] M. Pathan, R. K. Sitaraman, and D. Robinson, "CDN Analytics: A Primer", Advanced Content Delivery, Streaming, and Cloud Services, pp. 159-177, 2014.

[77] M. Pathan, R. K. Sitaraman, and D. Robinson, "CDN Modeling", Advanced Content Delivery, Streaming, and Cloud Services, 2014.

[78] A. Vakali and G. Pallis, "Content delivery networks: Status and trends", IEEE Internet Computing, vol. 7, (6), pp. 68-74, Nov. 2003.

[79] H. A. Tran, S. Hoceini, A. Mellouk, J. Perez, and S. Zeadally, "QoE-Based Server Selection for Content Distribution Networks", IEEE Transactions on Computers, vol. 63, (11), pp. 2803-2815, Nov. 2014.

[80] G. Paschos, E. Bastug, I. Land, G. Caire, and M. Debbah, "Wireless caching: Technical misconceptions and business barriers", IEEE Communications Magazine, vol. 54, (8), pp. 16-22, Aug. 2016. 
[81] N. Golrezaei, A. F. Molisch, A. G. Dimakis, and G. Caire, "Femtocaching and device-to-device collaboration: A new architecture for wireless video distribution", IEEE Communications Magazine, vol. 51, (4), pp. 142-149, Apr. 2013.

[82] M. Mohammadi Amiri and D. Gündüz, "Fundamental limits of coded caching: Improved delivery rate-cache capacity tradeoff", IEEE Transactions on Communications, vol. 65, (2), pp. 806-815, Feb. 2017.

[83] E. Baccelli, C. Mehlis, O. Hahm, T. C. Schmidt, and M. Wählisch, "Information Centric Networking in the IoT: Experiments with NDN in the Wild", Proceedings of the 1st ACM Conference on Information-Centric Networking, pp. 77-86, 2014.

[84] Z. Chen, N. Pappas, and M. Kountouris, "Probabilistic Caching in Wireless D2D Networks: Cache Hit Optimal versus Throughput Optimal”, IEEE Communications Letters, vol. 21, (3), pp. 584-587, Mar. 2017.

[85] J. Ma, J. Wang, and P. Fan, "A Cooperation-Based Caching Scheme for Heterogeneous Networks", IEEE Access, vol. 5, pp. 15 013-15 020, 2017.

[86] Z. Chen and M. Kountouris, "D2D caching vs. small cell caching: Where to cache content in a wireless network?", IEEE 17th International Workshop on Signal Processing Advances in Wireless Communications (SPAWC), pp. 16, Jul. 2016.

[87] G. S. Paschos, A. Destounis, L. Vigneri, and G. Iosifidis, "Learning to Cache With No Regrets", IEEE Conference on Computer Communications (INFOCOM), pp. 235-243, Apr. 2019.

[88] D. Liu and C. Yang, "Energy Efficiency of Downlink Networks With Caching at Base Stations", IEEE fournal on Selected Areas in Communications (FSAC), vol. 34, (4), pp. 907-922, Apr. 2016.

[89] J. Rao, H. Feng, C. Yang, Z. Chen, and B. Xia, "Optimal caching placement for D2D assisted wireless caching networks", IEEE International Conference on Communications (ICC), pp. 1-6, May 2016.

[90] W. Wang, R. Lan, J. Gu, A. Huang, H. Shan, and Z. Zhang, "Edge Caching at Base Stations With Device-to-Device Offloading”, IEEE Access, vol. 5, pp. 6399-6410, 2017. 
[91] F. Rezaei and B. H. Khalaj, "Stability, Rate, and Delay Analysis of Single Bottleneck Caching Networks", IEEE Transactions on Communications, vol. 64, (1), pp. 300-313, Jan. 2016.

[92] L. Breslau, Pei Cao, Li Fan, G. Phillips, and S. Shenker, "Web caching and Zipf-like distributions: evidence and implications", IEEE Conference on Computer Communications (INFOCOM) Proceedings, vol. 1, pp. 126-134, Mar. 1999.

[93] S. Traverso, M. Ahmed, M. Garetto, P. Giaccone, E. Leonardi, and S. Niccolini, "Temporal locality in today's content caching: Why it s and how to model it", SIGCOMM Comput. Commun. Rev., vol. 43, (5), pp. 5-12, Nov. 2013.

[94] N. Carlsson and D. Eager, "Ephemeral Content Popularity at the Edge and Implications for On-Demand Caching", IEEE Transactions on Parallel and Distributed Systems, vol. 28, (6), pp. 1621-1634, Jun. 2017.

[95] S. O. Somuyiwa, A. György, and D. Gündüz, "A Reinforcement-Learning Approach to Proactive Caching in Wireless Networks", IEEE fournal on Selected Areas in Communications, vol. 36, (6), pp. 1331-1344, Jun. 2018.

[96] A. Sadeghi, F. Sheikholeslami, and G. B. Giannakis, "Optimal and Scalable Caching for 5G Using Reinforcement Learning of Space-Time Popularities”, IEEE fournal of Selected Topics in Signal Processing, vol. 12, (1), pp. 180-190, Feb. 2018.

[97] S. Li, J. Xu, M. van der Schaar, and W. Li, "Trend-Aware Video Caching Through Online Learning”, IEEE Transactions on Multimedia, vol. 18, (12), pp. 2503-2516, Dec. 2016.

[98] D. Bertsimas and J. Tsitsiklis, Introduction to Linear Optimization, 1st ed. Athena Scientific, 1997.

[99] R. K. Ahuja, T. L. Magnanti, and J. B. Orlin, Network Flows: Theory, Algorithms, and Applications. Upper Saddle River, NJ, USA: Prentice-Hall, Inc., 1993.

[100] S. Boyd and L. Vandenberghe, Convex Optimization. New York, NY, USA: Cambridge University Press, Feb. 2004.

[101] D.-S. Chen, R. G. Batson, and Y. Dang, "Applied integer programming: Modeling and solution”, Jan. 2010. 
[102] A. S. Alfa, Applied Discrete-Time Queues, 2nd. Springer Publishing Company, Incorporated, 2015.

[103] D. Bertsekas and R. Gallager, Data Networks (2Nd Ed.) Upper Saddle River, NJ, USA: Prentice-Hall, Inc., 1992.

[104] F. Gebali, Analysis of Computer Networks, 2nd. Springer Publishing Company, Incorporated, 2015.

[105] L. Kleinrock, Theory, Volume 1, Queueing Systems. New York, NY, USA: Wiley-Interscience, 1975.

[106] K. Murty, Linear programming. John Wiley \& Sons, New York, 1983.

[107] Y. Nesterov and A. Nemirovskii, Interior-Point Polynomial Algorithms in Convex Programming. Society for Industrial and Applied Mathematics (SIAM), 1994.

[108] D.-Z. Du and P. M. Pardalos, Eds., Handbook of Combinatorial Optimization, 1-3 vols. Springer, Boston, MA, 1998.

[109] D. S. Hochbaum, Ed., Approximation Algorithms for NP-hard Problems. Boston, MA, USA: PWS Publishing Co., 1997.

[110] E. Aarts and J. K. Lenstra, "Local search in combinatorial optimization", John Wiley \& Sons, Inc., New York, NY, USA, 1997.

[111] F. W. Glover and M. Laguna, "Tabu Search", Springer US, New York, NY, USA, 1997.

[112] E. Aarts, J. Korst, and W. Michiels, "Simulated annealing", Search Methodologies: Introductory Tutorials in Optimization and Decision Support Techniques, Springer US,Boston, MA, pp. 187-210, 2005.

[113] M. Mitchell, “An introduction to genetic algorithms", MIT Press, Cambridge, MA, USA, 1996.

[114] H. A. Alameddine, L. Qu, and C. Assi, "Scheduling service function chains for ultra-low latency network services", International Conference on Network and Service Management (CNSM), pp. 1-9, Nov. 2017.

[115] C. Pham, N. H. Tran, and C. S. Hong, "Virtual Network Function Scheduling: A Matching Game Approach”, IEEE Communications Letters, vol. 22, (1), pp. 69-72, Jan. 2018. 
[116] E. Fountoulakis, Q. Liao, M. Stein, and N. Pappas, "Traversing Virtual Network Functions from the Edge to the Core: An End-to-End Performance Analysis", arXiv e-prints, arXiv:1811.02330, 2018. 
Part II

\section{Included Papers}




\section{Papers}

The papers associated with this thesis have been removed for copyright reasons. For more details about these see:

http://urn.kb.se/resolve?urn=urn:nbn:se:liu:diva-161732 


\section{INSTITUTE OF TECHNOLOGY}

Linköping Studies in Science and Technology. Dissertation No. 2016, 2019

Department of Science and Technology

Linköping University

SE-581 83 Linköping, Sweden

www.liu.se 